REVIEW

\title{
Sleep disordered breathing and its treatment in congestive heart failure
}

\author{
L J Cormican, A Williams
}

Heart 2005;91:1265-1270. doi: 10.1136/hrt.2004.048314

Sleep disordered breathing (SDB) is a common problem with adverse cardiorespiratory, endocrinological, and endothelial effects. Recent studies demonstrate an even higher prevalence of SDB in congestive heart failure (CHF) than in a randomly selected population, with up to $40 \%$ and $11 \%$ having Cheyne Stokes respiration-central sleep apnoea and obstructive sleep apnoea-hypopnoea syndromes, respectively. Randomised controlled trials of nocturnal respiratory support for SDB associated with CHF for up to three months demonstrate significant benefits in terms of improvements in left ventricular ejection fraction, markers of sympathetic system activity, and quality of life. Further randomised controlled trials of larger scale and longer duration are required to establish the role and benefit of this intervention for the treatment of this debilitating condition. The evidence for the higher prevalence of SDB in CHF, its pathogenesis, its pathophysiological consequences, and the emerging benefits of respiratory support are reviewed.

See end of article for authors' affiliations

Correspondence to: Dr Liam Cormican, Sleep Disorders Centre, St Thomas' Hospital, Lambeth Palace Road, London SE 1 7EH, UK; cormitron@ yahoo.com

Accepted 8 February 2005

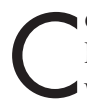
ongestive heart failure (CHF) remains a leading cause of morbidity and mortality worldwide. ${ }^{1}$ Randomised controlled trials have shown significant benefits of pharmacological treatment based on the attenuation of adrenergic drive through selective $\beta$ blockade $^{23}$ or manipulation of the renin-angiotensin-aldosterone system. ${ }^{4-6}$ More recently cardiac resynchronisation ${ }^{7}$ has developed as a new treatment modality for specific patients with CHF. However, the survival benefits manifested in such trials have yet to translate into a dramatic reduction in CHF mortality. ${ }^{8}{ }^{9}$

It is therefore important to identify and explore all of the factors that may alter the prognosis of heart failure, to facilitate the development of additional treatment options.

Sleep disordered breathing (SDB) in CHF is a burgeoning field of research, which offers insight into pathophysiological mechanisms and has treatment potential

Undiagnosed SDB is a common problem affecting up to $24 \%$ and $9 \%$ of randomly selected middle aged men and women, respectively, ${ }^{10}$ with $4 \%$ and $2 \%$ having obstructive sleep apnoea-hypopnoea syndrome (OSAHS).${ }^{10}$ Prevalence data on CSA in the healthy adult population are lacking.

There is, however, evidence of a higher prevalence of SDB in the heart failure population than in the normal population. ${ }^{11-13}$ Obstructive sleep apnoea is also associated with increased odds of developing heart failure independent of other risk factors. ${ }^{14}$

\section{DIAGNOSIS AND CLASSIFICATION}

The primary parameter used to quantify SDB is the apnoea-hypopnoea index (the mean number of apnoeic and hypopnoeic events an hour during a night's sleep). Five or more an hour are regarded as significant and are classified as either obstructive or central. Table $1^{15}$ outlines the diagnostic criteria for the classification of SDB.

Obstructive apnoeas and hypopnoeas result from complete or partial collapse of a narrowed pharynx, respectively. ${ }^{16}$ Central sleep apnoeas and hypopnoeas can result from either a reduction in central respiratory drive (as occurs in brainstem pathology or respiratory muscle weakness, thus associated with hypoventilation and hypercapnia) or an instability in feedback control of the central respiratory centre (as occurs in CHF, but it is often idiopathic and not associated with hypercapnia). ${ }^{17-19}$ Cheyne-Stokes respiration (CSR) is a form of periodic breathing with oscillations in tidal volume associated with central apnoea and hypopnoea, often referred to as CSR-CSA. However, as the purpose of this review is to focus on SDB in CHF, because of the similarity in pathophysiology of CSR-CSA and CSA, they will be regarded as one.

Table 2 outlines a basic classification of sleep studies. ${ }^{15}$ Attended nocturnal polysomnography is considered the ideal diagnostic modality for the diagnosis of the cause of SDB, although it is clearly not widely available. ${ }^{20}$

However, guidelines ${ }^{15}$ advise that level II and III studies are acceptable for the diagnosis and assessment of treatment for SDB in the adult population. There is not yet guidance for the use of these studies on the diagnosis and assessment of SDB in the CHF population. Level IV studies, a combination of continuous pulse rate and oxyhaemoglobin saturation recording, though not recommended for the diagnosis and classification of SDB, have a role as a screening tool for SDB in an adult population. Level III studies, which can also be performed in the home, record more detailed information (pulse rate,

Abbreviations: CANPAP, Canadian continuous positive airway pressure; $C H F$, congestive heart failure; CPAP, continuous positive airway pressure; CSA, central sleep apnoea; CSR, Cheyne-Stokes respiration; NYHA, New York Heart Association; OSAHS, obstructive sleep apnoea hypopnoea syndrome; $\mathrm{PCO}_{2}$, partial pressure of carbon dioxide; SDB, sleep disordered breathing 
Table 1 Diagnostic criteria for the classification of SDB (based on the American Academy of Sleep Medicine Task Force) ${ }^{15}$ on the basis of the combination of symptoms or signs and findings on overnight monitoring

\begin{tabular}{lll}
\hline Syndrome & Symptoms and signs & Overnight monitoring \\
\hline OSAHS & $\begin{array}{l}\text { Excessive daytime sleepiness not explained by other factors or two } \\
\text { or more of the following: choking or gasping during sleep; recurrent } \\
\text { awakenings from sleep; unrefreshing sleep; daytime fatigue; } \\
\text { impaired concentration }\end{array}$ & $\begin{array}{l}\text { Five or more obstructed breathing events/hour, any combination of } \\
\text { apnoea, hypopnoea, and respiratory effort related arousal }\end{array}$ \\
CSA-HS & $\begin{array}{l}\text { One or both of excessive daytime sleepiness and frequent nocturnal } \\
\text { arousals or awakenings }\end{array}$ & $\begin{array}{l}\text { Five or more central apnoeic and hypopnoeic events/hour and } \\
\text { normal daytime } \mathrm{PCO}_{2}(<6 \mathrm{kPa})\end{array}$ \\
CSR-CSA & CHF or cerebral neurological disease & $\begin{array}{l}\text { Three or more consecutive cycles of cyclical crescendo and decrescendo } \\
\text { change in breathing amplitude and five or more central apnoeic and } \\
\text { hypopnoeic events/hour or a cycle of crescendo-decrescendo change } \\
\text { in breathing amplitude lasting } 10 \text { minutes or more }\end{array}$
\end{tabular}

CHF, congestive heart failure; CSA, central sleep apnoea; CSR, Cheyne Stokes respiration; HS, hypopnoea syndrome; OSAHS, obstructive sleep apnoea-

hypopnoea syndrome; $\mathrm{PCO}_{2}$, partial pressure of carbon dioxide; $\mathrm{SDB}$, sleep disordered breathing.

oxyhaemoglobin saturation, abdominal and thoracic wall movement, airflow, and sleeping position). They allow the diagnosis of disordered breathing during assumed sleep and its classification and quantification of severity. Though not necessarily validated for the assessment of SDB in the context of CHF, level III studies are more widely available than level I or II studies for the assessment of SDB at a secondary care level through sleep disorders clinics.

\section{EPIDEMIOLOGY OF SLEEP DISORDERED BREATHING IN CONGESTIVE HEART FAILURE}

In a prospective study of 81 consecutive patients with predominantly New York Heart Association class I and II heart failure (caused by ischaemia, alcohol, and idiopathic cardiomyopathy) and a mean ejection fraction of $<30 \%, 51 \%$ of patients had significant evidence of SDB. Of those, $78 \%$ had CSA and $22 \%$ had OSAHS. ${ }^{11}$ In a population of 450 patients with CHF with symptoms of SDB referred for polysomnography studied retrospectively, the prevalence of SDB, CSA, and OSAHS was $61 \%, 29 \%$, and $32 \%$, respectively. ${ }^{12}$ Similarly in a series of 35 consecutive patients with CHF, the prevalence of the same disorders was $65 \%, 37 \%$, and $28 \%{ }^{13}$

There is some evidence that the prevalence of CSA is increased in CHF populations with increasing disease severity. In a study of consecutive patients presenting with acute left ventricular failure, the prevalence of SDB, CSRCSA, and OSAHS was $82 \%, 75 \%$, and $25 \%$, respectively, within one month of presentation and treatment. ${ }^{21}$ CSR-CSA syndrome affected up to $45 \%$ in a series of consecutive patients awaiting cardiac transplantation. ${ }^{22}$ However, the strength of this relation has recently been questioned. ${ }^{23}$

On the other hand, prospective studies of consecutive patients who have OSAHS provide evidence of left ventricular dysfunction when all other causes of left ventricular dysfunction have been excluded (coronary artery disease, CHF caused by cardiomyopathy or valvar heart disease, hypertension, and hypertrophic cardiomyopathy). ${ }^{24-25}$
Therefore, SDB can occur as a consequence of CHF but may also exacerbate the disease process

However, it must be highlighted that larger epidemiological studies are required to quantify more accurately the prevalence of SDB and its subclassifications in the CHF population. Such studies will also add to our understanding of the impact of more recently introduced treatment modalities such as $\beta$ blockade and biventricular pacemaker insertion on the prevalence of SDB, especially CSR-CSA, in CHF.

\section{PATHOGENESIS}

The pathogenesis of CSR-CSA in CHF has recently been elucidated.

Hyperventilation with reduction of arterial carbon dioxide pressure below a threshold is critical to the initiation of CSRCSA independent of circulation time. However, there is a significant correlation between lung to chemoreceptor circulation time and the length of the CSR-CSA cycle. ${ }^{18}$ Hyperventilation in the setting of CHF is believed to occur due to the stimulation of lung vagal irritant receptors as a consequence of pulmonary congestion as indicated by higher pulmonary capillary wedge pressure in patients with CHF associated with CSR-CSA than in those without. ${ }^{26}$

Hyperventilation may also occur due to increased ventilatory sensitivity to carbon dioxide, as patients with CHF associated with CSR-CSA have a greater ventilatory responsiveness to carbon dioxide than do those without. ${ }^{27}$ Risk factors for the occurrence of CSR-CSA in a CHF population are male sex, atrial fibrillation, age greater than 60 , and daytime hypocapnia. ${ }^{12}$

The reason for the increased prevalence of OSAHS in CHF is less clear. The coexistence of both may also be a function of their respective high prevalence in the adult population. ${ }^{10}$

On the other hand, sleep onset is associated with loss of pharyngeal dilator muscle tone, which in the setting of normal pharyngeal anatomy is not associated with airway compromise. In patients with OSAHS, the pharynx is

Table 2 Types of sleep studies (based on the American Academy of Sleep Medicine Task Force) ${ }^{15}$

\begin{tabular}{|c|c|c|c|}
\hline Level & Components & $\begin{array}{l}\text { Location } \\
\text { performed }\end{array}$ & Comment \\
\hline 1 & $\begin{array}{l}\text { Electroencephalogram, electro-oculogram, submental EMG, } \\
\text { nasal/oral airflow, respiratory movement, oximetry, ECG, } \\
\text { anterior tibialis EMG, sleeping position }\end{array}$ & $\begin{array}{l}\text { Sleep } \\
\text { laboratory }\end{array}$ & $\begin{array}{l}\text { Complete attended study; facilitates determination of wake and sleep } \\
\text { states, sleep stages, and disturbance, } \mathrm{AHI} \text {, and detection of sleep } \\
\text { pathology unrelated to SDB }\end{array}$ \\
\hline$\|$ & Same as level I & Home & Same as level I but an unattended study \\
\hline III & $\begin{array}{l}\text { Partial study measuring nasal/oral airflow, respiratory } \\
\text { movement, oximetry, pulse rate, sleep position }\end{array}$ & Home & $\begin{array}{l}\text { Unattended study; allows detection of respiratory and cardiac events but } \\
\text { no information about wake and sleep states and stages or sleep } \\
\text { disturbance and non-SDB sleep pathology }\end{array}$ \\
\hline IV & Pulse rate, oximetry & Home & Unattended study; least expensive, useful screening tool for OSAHS \\
\hline
\end{tabular}


anatomically narrowed and highly compliant; hence, the changes of sleep onset result in pharyngeal occlusion. ${ }^{28}$ Obesity is a risk factor for OSAHS because of the layering of fat adjacent to the pharynx narrowing its lumen, ${ }^{29}$ but the prevalence of obesity in the CHF populations studied was not very high. In prevalence studies, the patients studied were clinically overweight (mean body mass index $\left.28 \mathrm{~kg} / \mathrm{m}^{2}\right)^{11}$ and mildly obese (mean body mass index $32.3 \mathrm{~kg} / \mathrm{m}^{2}$ ). ${ }^{12}$ Pharyngeal muscle tone can be altered during the oscillations of ventilatory drive that accompany CSR, resulting in loss of pharyngeal dilator action, ${ }^{30}$ in addition to increased pharyngeal oedema caused by increased fluid shift centrally from the lower limbs, which occurs while the patient is supine at night. ${ }^{31}$ Both of these factors can compromise the patency of the upper airway.

Though SDB in patients with CHF can be classified as either CSR-CSA or OSAHS in nature, ${ }^{11}$ there is evidence of a relation between the pathophysiology of both.

The same patient can have both OSAHS and CSR-CSA and a shift from one type to another can be observed during sleep, which is associated with a decrease in partial pressure of carbon dioxide $\left(\mathrm{PCO}_{2}\right)$ and lengthening of the circulation time. ${ }^{32}$ The reasons for such are a matter of debate. One factor that may be a determinant of apnoea type is the arterial carbon dioxide as reflected by $\mathrm{PCO}_{2}$. Hyperventilation as already mentioned occurs in CHF patients as a result of stimulation of lung vagal irritant receptors ${ }^{26}$ and altered ventilatory responsiveness to carbon dioxide. ${ }^{27}$ The consequent reduction of arterial $\mathrm{PCO}_{2}$ below the apnoeic threshold (the level of arterial $\mathrm{PCO}_{2}$ below which ventilation ceases) triggers the onset of CSR-CSA. ${ }^{27}$ On the other hand, OSAHS is not associated with a fall in $\mathrm{PCO}_{2} \cdot{ }^{32}$ The close link between overnight lengthening of the circulation time and reductions in arterial $\mathrm{PCO}_{2}$ strongly suggests that the fall in $\mathrm{PCO}_{2}$ and shift in apnoea type are linked to an overnight deterioration in cardiac function.

\section{PATHOPHYSIOLOGICAL CONSEQUENCES}

The pathophysiological consequences of OSAHS in CHF are multiple.

Repeated upper respiratory obstructive events result in negative intrathoracic pressure, increased systolic transmural pressure, increased left ventricular afterload, and hence reduced stroke volume and cardiac output. ${ }^{33}$ Increased negative intrathoracic pressure results in increased venous return, right ventricular volume overload, leftward shift of the interventricular septum, impaired left ventricular filling, and reduced stroke volume. ${ }^{34}$

Increased sympathetic nervous system activity is a central feature of obstructive sleep apnoea. The pulmonary stretch receptor mediated reflex, which normally suppresses central sympathetic discharge during normal breathing, ceases during apnoea, facilitating sympathetic outflow. ${ }^{35}$ The associated hypoxia and hypercapnia further augment sympathetic activity by simulating peripheral and central chemoreceptors. The consequences are increased heart rate, vasoconstriction, and raised peripheral vascular resistance..$^{36} 37$

The pathophysiological impact of OSAHS extends into wakefulness, with it now being recognised as an independent risk factor for hypertension ${ }^{38} 39$ and it being associated with left ventricular hypertrophy in normotensive patients. ${ }^{40}$

Obstructive sleep apnoea syndrome is now recognised as an independent risk factor for increased insulin resistance. Furthermore, treatment with continuous positive airway pressure (CPAP) has been shown to increase insulin sensitivity in these patients. ${ }^{41}$

There is also evidence that OSAHS may have potential detrimental endothelial effects. Patients with OSAHS have higher plasma $\mathrm{C}$ reactive protein concentrations ${ }^{42}$ than controls, they have signs of increased oxidative stress, such as increased reactive oxygen species production in neutrophils, ${ }^{43}$ and they have increased serum concentrations of intracellular adhesion molecule 1 and vascular cell adhesion molecule $1 .^{44}$

There are some reports that OSAHS alone can also act as an independent risk factor for the development of left ventricular dysfunction. In patients without a history of CHF or coronary artery disease, the presence of OSAHS is associated with evidence of left ventricular systolic ${ }^{24}$ and diastolic dysfunction. ${ }^{24} 25$ Nocturnal CPAP for six months results in the correction of these indices. Furthermore, normotensive patients with OSAHS have increased left ventricular wall thickness in comparison with controls. ${ }^{40}$

The presence of CSR-CSA additionally has an adverse prognostic impact and pathophysiological burden on patients with CHF. It is associated with a higher mortality even after adjustment for other disease severity risk factors. ${ }^{45}{ }^{46}$ The adverse effects of CSR-CSA probably arise from similar factors described for OSAHS including intermittent hypoxia, frequent arousals from sleep, sympathetic system activation, and apnoea related surges in blood pressure and heart rate, but without the effects of negative intrathoracic pressure during apnoeic events.

\section{EVIDENCE FOR THE TREATMENT OF SDB IN CHF}

There is compelling evidence for the treatment of OSAHS with CPAP irrespective of whether patients have CHF. ${ }^{47} 48$

The physiological benefits are reduced frequency and severity of desaturations, heart rate variability, apnoea, hypopnoeic events, ${ }^{49}$ daytime somnolence, ${ }^{50}$ and improved control of hypertension ${ }^{51}$ and neuropsychological symptoms. $^{52}$

There is also evidence that the treatment of OSAHS in CHF with CPAP has additional positive physiological and clinical benefits by abolishing apnoea related hypoxia, lowering nocturnal blood pressure, improving sleep quality ${ }^{53}$ and ejection fraction, ${ }^{54-56}$ and reducing catecholamine produc$\operatorname{tion}^{56}$ (table 3). Two randomised controlled trials of CPAP for OSAHS associated with CHF have confirmed that these improvements in ejection fraction are significant $\left(5 \%{ }^{56}\right.$ and $8.8 \%^{55}$ ) and that they are associated with improvements in symptoms. ${ }^{56}$

Even in the absence of evidence of CHF or a primary cardiac disease, there is some evidence (albeit from uncontrolled trials with small numbers) that the treatment of OSAHS for six months or longer results in a significant increase in left ventricular ejection fraction. ${ }^{24-25}$

These changes are believed to be caused by the relative increase in intrathoracic pressure due to CPAP, resulting in a reduction in cardiac transmural pressure. The reduction in transmural pressure in conjunction with the reduction of nocturnal blood pressure leads to a reduction in left ventricular afterload. ${ }^{53}$

However, larger and longer term randomised controlled studies recruiting treatment naive patients with OSAHS without cardiovascular morbidity at baseline are required to determine whether OSAHS can cause CHF directly.

There is also evidence from randomised controlled trials that CPAP has a significant beneficial effect on CSR-CSA caused by CHF when applied for at least 1-3 months ${ }^{57-60}$ $\left(\right.$ table $\left.4^{57-63}\right)$. The benefits were a reduced apnoea-hypopnoea index and improved ejection fraction (6.5\% to $8.6 \%)$, New York Heart Association (NYHA) functional status, and symptom score. This is postulated to be caused by reduced minute ventilation, with an increase in arterial carbon dioxide pressure (possibly above the apnoeic threshold) during sleep as a consequence of reduced lung vagal irritant 
Table 3 Randomised controlled trials of nocturnal respiratory support in patients with OSAHS associated with CHF

\begin{tabular}{|c|c|c|c|c|c|c|c|}
\hline \multirow[b]{2}{*}{ Trial } & \multicolumn{3}{|c|}{ Patient characteristics } & \multirow[b]{2}{*}{ Intervention } & \multirow[b]{2}{*}{$\begin{array}{l}\text { Duration of } \\
\text { treatment }\end{array}$} & \multirow[b]{2}{*}{$\begin{array}{l}\text { No of } \\
\text { patients }\end{array}$} & \multirow[b]{2}{*}{ Cardiovascular outcomes } \\
\hline & CHF cause & $\begin{array}{l}\text { NYHA } \\
\text { class }\end{array}$ & $\begin{array}{l}\text { Baseline LVEF } \\
(\%)\end{array}$ & & & & \\
\hline $\begin{array}{l}\text { Kaneko } \\
\text { et a } \text { p }^{55}\end{array}$ & ICM, DCM & 2.3 & 25.0 & CPAP & 1 month & 24 & $\begin{array}{l}\text { 8.8\% increase in LVEF, reduced LVESD, reduced heart rate } \\
\text { and SBP }\end{array}$ \\
\hline $\begin{array}{l}\text { Mansfield } \\
\text { et al }\end{array}$ & Not stated & 2.2 & 37.3 & CPAP & 3 months & 55 & $\begin{array}{l}5 \% \text { increase in LVEF, reduced fatigue and overnight urinary } \\
\text { noradrenaline excretion, increased disease mastery and } \\
\text { emotional wellbeing (CHFQ) }\end{array}$ \\
\hline
\end{tabular}

CHFQ, Guyatt chronic heart failure questionnaire; CPAP, continuous positive airway pressure; DCM, dilated cardiomyopathy; ICM, ischaemic cardiomyopathy; LVEF, left ventricular ejection fraction; LVESD, left ventricular end systolic dimension; NYHA, New York Heart Association; SBP, systolic blood pressure.

receptor stimulation due to reduced pulmonary congestion. ${ }^{64}$ Concern has been raised over the possible adverse haemodynamic effects of the use of CPAP in severe CHF (NYHA class III to IV) associated with atrial fibrillation in one study. ${ }^{65}$

Overall, the sample sizes of these studies are small, ${ }^{57-60}$ the periods of follow up are short, and possibly as a consequence only one study has reported a reduction in mortality. ${ }^{60}$

Larger longer term follow up studies are required to address the mortality benefits and to clarify the subgroups of patients with CHF who are susceptible to the potential adverse haemodynamic effects of the use CPAP.

Additional forms of respiratory support have been examined in this context.

Pressure support adaptive servo- (non-invasive) ventilation, a hybrid form of respiratory support that can cycle between pressure support during hypopnoea and ventilatory support during apnoea, is as effective as CPAP for the treatment of CSR-CSA in patients with CHF in terms of indices of $\mathrm{SDB},{ }^{61}$ neurohormonal activation, and reduced daytime somnolence over a period of a month. ${ }^{62}$

Bilevel non-invasive ventilation has also been proved to be an effective alternative to CPAP in the treatment of CSR-CSA caused by CHF. ${ }^{63}$

The first randomised controlled trials of respiratory support for the treatment of OSAHS associated with CHF have recently been published ${ }^{55}{ }^{56}$ (table 3 ). In both, patients were treated with CPAP for periods of $1-3$ months. In comparison with the control groups, the CPAP treated groups exhibited an increase in left ventricular ejection fraction of $5 \%{ }^{56}$ and $8.8 \% .^{55}$
Furthermore, mean daytime systolic blood pressure ( 126 to $116 \mathrm{~mm} \mathrm{Hg}$ ), heart rate (68 to 64 beats/min), and left ventricular end systolic dimension (54.5 to $51.7 \mathrm{~mm}$ ) changed significantly. Sympathetic nervous system activity as measured by overnight urinary noradrenaline (norepinephrine) excretion was reduced in the treatment group and indices of quality of life were improved (fatigue, disease mastery, and emotional wellbeing as measured by the chronic heart failure questionnaire). ${ }^{56}$

This treatment for this specific CHF patient population compares favourably with the effects of $\beta$ blockade and angiotensin converting enzyme inhibition ${ }^{66}$ in CHF as shown by randomised controlled trials. ${ }^{67}$ However, as mentioned above, this evidence is limited by a lack of a demonstrable impact on mortality, possibly as a result of sample size and the duration of follow up.

Larger prospective trials such as the ongoing CANPAP (Canadian continuous positive airway pressure) ${ }^{68}$ trial are required to delineate the precise benefit and roles of CPAP in the treatment of SDB in CHF.

\section{OTHER TREATMENTS}

Nocturnal supplemental oxygen in the context of CSR-CSA associated with CHF, though abolishing apnoea related hypoxia and alleviating CSR-CSA ${ }^{69}{ }^{70}$ does not cause improvements in cardiac function or quality of life over a period of one month. ${ }^{71}$

Oral theophylline treatment of patients with SDB associated with CHF reduces the apnoea-hypopnoea index and duration of arterial oxygen desaturation during sleep but has

Table 4 Randomised controlled (and crossover) trials of nocturnal respiratory support in patients with CSR-CSA associated with $\mathrm{CHF}$

\begin{tabular}{|c|c|c|c|c|c|c|c|}
\hline \multirow[b]{2}{*}{ Trial } & \multicolumn{3}{|c|}{ Patient characteristics } & \multirow[b]{2}{*}{ Intervention } & \multirow[b]{2}{*}{$\begin{array}{l}\text { Duration of } \\
\text { treatment }\end{array}$} & \multirow[b]{2}{*}{$\begin{array}{l}\text { No of } \\
\text { patents }\end{array}$} & \multirow[b]{2}{*}{ Cardiovascular outcomes } \\
\hline & $\begin{array}{l}\text { CHF } \\
\text { cause }\end{array}$ & $\begin{array}{l}\text { NYHA } \\
\text { class }\end{array}$ & $\begin{array}{l}\text { Baseline } \\
\text { LVEF (\%) }\end{array}$ & & & & \\
\hline Naughton et a ${ }^{57}$ & $\begin{array}{l}\text { ICM } \\
\text { DCM }\end{array}$ & 2.5 & 18.3 & CPAP & 1 month & 18 & $\begin{array}{l}6.5 \% \text { increase in LVEF, reduced nocturnal urine and daytime } \\
\text { serum noradrenaline }\end{array}$ \\
\hline Naughton et $a^{58}$ & $\begin{array}{l}\text { ICM } \\
\text { DCM }\end{array}$ & 2.5 & 21.2 & CPAP & 3 months & 29 & $\begin{array}{l}7.7 \% \text { increase in LVEF, reduced fatigue and dyspnoea, } \\
\text { increased emotional well being and disease mastery (CHFQ) }\end{array}$ \\
\hline Granton et a $1^{59}$ & $\begin{array}{l}\text { ICM } \\
\text { DCM }\end{array}$ & 2.4 & 24 & CPAP & 3 months & 17 & $\begin{array}{l}8.6 \% \text { increase in LVEF, reduced dyspnoea and fatigue } \\
\text { (CHFQ) }\end{array}$ \\
\hline Sin et $a^{60}$ & ICM, & & NA & CPAP & 3 months & 66 & $\begin{array}{l}8 \% \text { increase in LVEF, } 81 \% \text { relative risk reduction in mortality } \\
\text { and transplantation rate }\end{array}$ \\
\hline Teschler et $a^{61}$ & $\begin{array}{l}\mathrm{ICM} \\
\mathrm{DCM}\end{array}$ & 2.9 & $\begin{array}{l}\text { Fractional } \\
\text { shortening } \\
0.19\end{array}$ & $\begin{array}{l}\text { APSSV, Bi-V, CPAP, } \\
\text { supplemental oxygen }\end{array}$ & $\begin{array}{l}4 \text { nights } \\
\text { (crossover } \\
\text { trial) }\end{array}$ & 14 & $\begin{array}{l}\text { APSSV reduced AHI and arousal index more than did } \\
\text { CPAP, bilevel ventilation or oxygen supplementation; } \\
\text { change in LVEF not measured }\end{array}$ \\
\hline Pepperell et $\left.a\right|^{162}$ & $\begin{array}{l}\text { ICM } \\
\text { DCM }\end{array}$ & 2.7 & 36.5 & APSSV & 1 month & 30 & $\begin{array}{l}\text { Reduced serum BNP, urinary metadrenaline, and daytime } \\
\text { somnolence; change in LVEF not measured }\end{array}$ \\
\hline Kohnlein et $a l^{163}$ & $\begin{array}{l}\mathrm{ICM} \\
\mathrm{DCM}\end{array}$ & 2.8 & 23.8 & $\mathrm{Bi}-\mathrm{V} / \mathrm{CPAP}$ & $\begin{array}{l}1 \text { month } \\
\text { (crossover } \\
\text { trial) }\end{array}$ & 18 & $\begin{array}{l}\text { Bilevel ventilation and CPAP equally improved circulation } \\
\text { time; improved sleep quality, reduced daytime fatigue (SF- } \\
\text { 36) and NYHA class; change in LVEF not measured }\end{array}$ \\
\hline
\end{tabular}

APSSV, adaptive pressure support servoventilation; Bi-V, bilevel non-invasive ventilation; BNP, brain natriuretic peptide; NA, not available; SF-36, short form 36 questionnaire. 
not been shown to cause improvements in ventricular function, quality of life, or clinical outcomes. ${ }^{72}$ Atrial overdrive pacing has recently been shown by one group ${ }^{73}$ to reduce the number of episodes of central and obstructive apnoea in a cohort of patients with SDB without CHF. The mechanism by which this occurs is a matter of debate. It may be related to the effect of an augmentation in cardiac output reducing pulmonary congestion, a stimulus for hyperventilation, and to a reduction in circulation time. Further studies are awaited to determine whether this effect can be reproduced.

Lifestyle modification resulting in weight loss reduces the severity of OSAHS, ${ }^{74}$ possibly through a decrement in upper airway collapsibility ${ }^{75}$ in an obese non-CHF population. Though there is no such evidence for an obese CHF population, presumably the same should occur.

\section{CONCLUSION}

The presence of SDB presents another treatment opportunity in CHF. There is now a burgeoning field of evidence that respiratory support for these patients has considerable physiological benefits. Larger longer term studies are required to determine whether these benefits have an impact on mortality. Increased awareness of the prevalence and pathophysiological implications of SDB in CHF is essential to promote and encourage the further development of this facet of treatment in CHF.

\section{Authors' affiliations}

L J Cormican, A Williams, Sleep Disorders Centre, Guy's and St Thomas' NHS Trust, London, UK

\section{REFERENCES}

1 Jessup M, Brozena S. Heart failure. N Engl J Med 2003;348:2007-18.

2 Anon. CIBIS Investigators and Committees. A randomised trial of B-blockade in heart failure. The cardiac insufficiency bisoprolol study (CIBIS). Circulation 1994;90:1765-73.

3 MERIT-HF Study Group. Effect of metoprolol CR/XL in chronic heart failure: metoprolol CR/XL randomised international trial in congestive heart failure (MERIT-HF). Lancet 1999;353:2001-7.

4 Garg R, Yusuf S. Overview of randomized trials of angiotensin-converting enzyme inhibitors on mortality and morbidity in patients with heart failure. JAMA 1995;273:1450-6.

5 Dahlof B, Devereux R, Kjeldsen SE, et al. Cardiovascular morbidity and mortality in the losartan intervention for endpoint reduction in hypertension study (LIFE): a randomised trial against atenolol. Lancet 2002;359:995-1003.

6 Pitt B, Zannad F, Remme W, et al. The effect of spironolactone on morbidity and mortality in patients with severe heart failure. N Engl J Med 1999;341:709-17.

7 Cazeau S, Leclercq C, Lavergne T, et al. Effects of multisite biventricular pacing in patients with heart failure and intraventricular conduction delay. N Engl J Med 2001;344:873-80.

8 Konstam M. Progress in heart failure management? Lessons from the real world. Circulation 2000;102:1076-8.

9 Jong $\mathbf{P}$, Vowinckel E, Liu $P$, et al. Prognosis and determinants of survival in patients newly hospitalised with heart failure: a population based study. Arch Intern Med 2002; 162:1689-94.

10 Young T, Palta M, Dempsey J, et al. The prevalence of sleep disordered breathing among middle-aged adults. N Engl J Med 1993;328:1230-5.

11 Javaheri S, Parker T, Liming J, et al. Sleep apnoea in 81 ambulatory male patients with stable heart failure: types and their prevalences, consequences, and presentations. Circulation 1998:97:2154-9.

12 Sin D, Fitzgerald F, Parker J, et al. Risk factors for central and obstructive sleep apnoea in 450 men and women with congestive heart failure. Am J Respir Crit Care Med 1999;160:1101-6.

13 Banno K, Shiomi T, Sasanabe R, et al. Sleep disordered breathing in patients with idiopathic cardiomyopathy. Circ J 2004;68:338-42.

14 Shahar E, Whitney C, Redline S, et al. Sleep disordered breathing and cardiovascular disease: cross sectional results of the sleep heart health study. Am J Respir Crit Care Med 2001;163:19-25.

15 American Academy of Sleep Medicine Task Force. Sleep related breathing disorders in adults: recommendations for syndrome definition and measurement techniques in clinical research. Sleep 1999;22:667-89.

16 Bradley T, Brown I, Grossman R, et al. Pharyngeal size in snorers, nonsnorers, and patients with obstructive sleep apnea. N Engl J Med 1986:328:1230-5

17 Bradley T, McNicholas W, Rutherford R, et al. Clinical and physiologic heterogeneity of the central sleep apnea syndrome. Am Rev Respir Dis $1986 ; 134: 217-21$.
18 Naughton M, Bernard D, Tam A, et al. Role of hyperventilation in the pathogenesis of central sleep apnoeas in patients with congestive heart failure. Am Rev Respir Dis 1993; 148:330-8.

19 Cherniack N. Apnea and periodic breathing during sleep. N Engl J Med 1999:341:985-7.

20 Flemons W, Douglas N, Kuna S, et al. Access to diagnosis and treatment of patients with suspected sleep apnea. Am J Respir Crit Care Med 2004; 169:668-72.

21 Tremel F, Pepin J, Veale D, et al. High prevalence and persistence of sleep apnoea in patients referred for acute left ventricular failure and medically treated over 2 months. Eur Heart J 1999;20:1201-9.

22 Lofaso F, Vercheuren P, Rande J, et al. Prevalence of sleep disordered breathing in patients on a heart transplant list. Chest 1994;106:1689-94.

23 Lanfranchi P, Somers V, Braghiroli A, et al. Central sleep apnea in left ventricular dysfunction: prevalence and implications for arrhythmic risk. Circulation 2003; 107:727-32.

24 Laaban J, Pascal-Sebaoun S, Bloch E, et al. Left ventricular systolic dysfunction in patients with obstructive sleep apnoea syndrome. Chest 2002;122:1133-8.

25 Alchanatis W, Tourkohoriti G, Kosmas E, et al. Evidence for left ventricular dysfunction in patients with obstructive sleep apnoea syndrome. Eur Respir J 2002;20:1239-45.

26 Solin $\mathbf{P}$, Bergin P, Richardson M. Influence of pulmonary capillary wedge pressure on central apnoea in heart failure. Circulation 1999;99:1574-9.

27 Javaheri S. A mechanism of central sleep apnoea in patients with heart failure. N Engl J Med 1999;341:949-54

28 Remmers J, Degroot W, Saurland E, et al. Pathogenesis of upper airway occlusion during sleep. J Appl Physiol 1978;44:931-8.

29 Horner R, Mohiaddin R, Lowell D, et al. Sites and sizes of fat deposits around the pharynx in obese subjects with obstructive sleep apnoea and weight matched controls. Eur Respir J 1989;2:613-22.

30 Alex C, Onal E, Lopata M. Upper airway occlusion during sleep in patients with Cheyne-Stokes respiration. Am Rev Respir Dis 1986;133:42-5.

31 Shepard J, Pevernagie D, Stanson A, et al. Effects of changes in central venous pressure on upper airway size in patients with obstructive sleep apnoea. Am J Respir Crit Care Med 1996;153:250-4.

32 Tkacova R, Niroumand N, Lorenzi-Filho G, et al. Overnight shift from obstructive to central apneas in patients with heart failure: role of PCO2 and circulatory delay. Circulation $2001 ; 103: 238-43$

33 Bradley T, Hall M, Ando S, et al. Hemodynamic effects of simulated obstructive apneas in humans with and without heart failure. Chest 2001;119:1827-35

34 Shiomi T, Guilleminault C, Stoohs R, et al. Leftward shift of the interventricular septum and pulsus paradoxus in obstructive sleep apnoea. Chest $1991 ; 100: 894-902$

35 Somers V, Dyken $M$, Clary M, et al. Sympathetic neural mechanisms in obstructive sleep apnoea. J Clin Invest 1995;96:1897-904.

36 Morgan B, Denahan T, Ebert T, et al. Neurocirculatory consequences of negative intrathoracic pressure vs. asphyxia during voluntary apnoea. J Appl Physiol 1993;74:1969-75.

37 Somers V, Mark A, Zavala D, et al. Contrasting effects of hypoxia and hypercapnia on ventilation and sympathetic activity in humans. J Appl Physiol 1989;67:2101-6.

38 Williams A, Houston D, Finberg $S$, et al. Sleep apnoea syndrome and essential hypertension. Am J Cardiol 1985;55:1019-22.

39 Lavie $\mathbf{P}$, Herer P, Hoffstein V. Obstructive sleep apnoea syndrome as a risk factor for hypertension: population study. BMJ 2000;320:479-82.

40 Hedner J, Ejnell H, Caidahl K. Left ventricular hypertrophy independent of hypertension in patients with obstructive sleep apnoea. J Hypertens 1990;8:941-6.

41 Harsch I, Schahin S, Radespiel-Troger M, et al. Continuous positive airway pressure treatment rapidly improves insulin sensitivity in patients with obstructive sleep apnea syndrome. Am J Respir Crit Care Med 2004; 169:156-62

42 Shamsuzzaman A, Winnicki $M$, Lanfranchi $P$, et al. Elevated $C$-reactive protein in patients with obstructive sleep apnea. Circulation 2002; 105:2462-4

43 Schulz R, Mahmoudi S, Hattar K, et al. Enhanced release of superoxide from polymorphonuclear neutrophils in obstructive sleep apnoea: impact of continuous positive airway pressure therapy. Am J Respir Crit Care Med 2000;162:566-70

44 El-Solh A, Mador M, Sikka $P$, et al. Adhesion molecules in patients with coronary artery disease and moderate to severe obstructive sleep apnoea. Chest 2002;121:1541-7.

45 Hanly P, Zuberi-Khokh H. Increased mortality associated with Cheyne-Stokes respiration in patients with congestive heart failure. N Engl J Med 1996; 153:272-6

46 Lanfranchi P, Braghiroli A, Bosimini E, et al. Prognostic value of nocturnal Cheyne-Stokes respiration in chronic heart failure. Circulation 1999:99:1435-40

47 Strolls DJ, Rogers R. Obstructive sleep apnoea. N Engl J Med 1996;334:99-104.

48 Engleman H, Martin S, Kingshott R, et al. Randomised placebo controlled trial of daytime function after continuous positive airway pressure (CPAP) therapy for sleep apnoea/hypopnoea syndrome. Thorax 1998;53:342-5.

49 Marrone O, Ferrara G, Macaluso C. Sleep related disorders and internal diseases. Berlin: Spinger, 1987:375-9.

50 Lamphere J, Roehrs T, Wittig R, et al. Recovery of alertness after CPAP in apnea. Chest 1989:96:1363-7.

51 Faccenda J, Mackay T, Boon N, et al. Randomized placebo-controlled trial of continuous positive airway pressure on blood pressure in the sleep apneahypopnea syndrome. Am J Respir Crit Care Med 2001;163:344-8. 
52 Derderian S, Bridenbaugh R, Rajagopal K. Neuropsychologic symptoms in obstructive sleep apnea improve after treatment with nasal continuous positive airway pressure. Chest 1988;94:1023-7.

53 Tkacova R, Rankin F, Fitzgerald F, et al. Effects of continuous positive airway pressure on obstructive sleep apnoea and left ventricular afterload in patients with heart failure. Circulation 1998;98:2269-75.

54 Malone S, Liu P, Holloway R, et al. Obstructive sleep apnoea in patients with dilated cardiomyopathy: effects of continuous positive airway pressure. Lancet 1991;338:1480-4

55 Kaneko Y, Floras J, Usui K, et al. Cardiovascular effects of continuous positive airway pressure in patients with heart failure and obstructive sleep apnea. N Engl J Med 2003;348:1233-41

56 Mansfield D, Gollogly N, Kaye D, et al. Controlled trial of continuous positive airway pressure in obstructive sleep apnea and heart failure. Am J Respir Crit Care Med 2004:169:361-6.

57 Naughton M, Bernard D, Liu P, et al. Effects of nasal CPAP on sympathetic activity of patients with heart failure and central sleep apnoea. Am J Respir Crit Care Med 1995; 152:473-9.

58 Naughton M, Liu P, Bernard D, et al. Treatment of congestive heart failure and Cheyne-Stokes respiration during sleep by continuous positive airway pressure. Am J Respir Crit Care Med 1995;151:92-7.

59 Granton J, Naughton M, Bernard D, et al. CPAP improves inspiratory muscle strength in patients with heart failure and central sleep apnoea. Am J Respir Crit Care Med 1996;153:277-82.

60 Sin D, Logan A, Fitzgerald F, et al. Effects of continuous positive airway pressure on cardiovascular outcomes in heart failure patients with and without Cheyne-Stokes respiration. Circulation 2000;102:61-6.

61 Teschler H, Dohring J, Wang Y-M, et al. Adaptive pressure support servoventilation, a novel treatment for Cheyne-Stokes respiration in heart failure. Am J Respir Crit Care Med 2001;164:614-9.

62 Pepperell J, Maskell N, Jones D, et al. A randomised controlled trial of adaptive ventilation for Cheyne-Stokes breathing in heart failure. Am J Respir Crit Care Med 2003;168:1109-14.

63 Kohnlein T, Welte T, Tan L, et al. Assisted ventilation for heart failure patients with Cheyne-Stokes respiration. Eur Respir J 2002;20:934-41.
64 Naughton M, Bernard D, Rutherford R, et al. Effect of continuous positive airway pressure on central sleep apnoea and nocturnal pCO2 in heart failure. Am J Respir Crit Care Med 1994; 150:1598-604.

65 Liston R, Deegan P, McCreery C, et al. Haemodynamic effects of nasal continuous positive airway pressure in severe congestive heart failure. Eur Respir J 1995;8:430-5.

66 Konstam M, Rousseau M, Kronenberg $M$, et al. Effects of the angiotensin converting enzyme inhibitor enalapril on the long-term progression of left ventricular dysfunction in patients with heart failure. SOLVD Investigators. Circulation 1992:86:431-8.

67 Lechat $\mathbf{P}$, Packer $M$, Chalon S, et al. Clinical effects of beta-adrenergic blockade in chronic heart failure. Circulation 1998;98:1184-91.

68 Bradley T, Logan A, Floras J, CANPAP Investigators. Rationale and design of the Canadian continuous positive airway pressure trial for congestive heart failure patients with central sleep apnoea-CANPAP. Can J Cardiol 2001;17:677-84.

69 Franklin K, Eriksson P, Sahlin C, et al. Reversal of central sleep apnoea with oxygen. Chest 1997;111:163-9

70 Krachman S, D'Alonzo G, Berger T, et al. Comparison of oxygen therapy with nasal continuous positive airway pressure on Cheyne-Stokes respiration during sleep in congestive heart failure. Chest 1999:116:1550-7.

71 Staniforth A, Kinnear W, Starling R, et al. Effect of oxygen on sleep quality, cognitive function and sympathetic activity in patients with chronic heart failure and Cheyne-Stokes respiration. Eur Heart J 1998;19:922-8.

72 Javaheri S, Parker T, Wexler L, et al. Effect of theophylline in sleep disordered breathing in heart failure. N Engl J Med 1996;335:562-7.

73 Garrigue S, Bordier P, Jais S, et al. Benefit of atrial pacing in sleep apnea syndrome. N Engl J Med 2002;346:404-12.

74 Rubinstein I, Colapinto N, Rotstein L, et al. Improvement in upper airway function after weight loss in patients with obstructive sleep apnea. Am Rev Respir Dis 1988; 138:1192-5.

75 Schwartz A, Gold A, Schubert N, et al. Effect of weight loss on upper airway collapsibility in obstructive sleep apnea. Am Rev Respir Dis $1991 ; 144: 494-8$

\section{IMAGES IN CARDIOLOGY}

\section{Cardiac angiosarcoma: diagnosis by coronary angiography}

A 55 year old man was admitted to hospital after collapsing while playing golf. During assessment in the emergency department the patient became unconscious and lost cardiac output associated with a sinus bradycardia of 40 beats/min, some nonspecific changes in the inferior ECG leads, and normal myocardial injury markers. Coronary angiography demonstrated normal coronary arteries; however, a branch of the right coronary artery (RCA) supplying the right atrium (RA) was associated with a tissue blush (panel A). Transthoracic echocardiography (TTE) confirmed a mass in the RA and a global pericardial effusion (panel B). Transoesophageal echocardiography (TOE) showed a localised $3.5 \times 3.5 \mathrm{~cm}$ tumour of the RA anterior wall (panel C). A computed tomographic (CT) scan of the chest showed no evidence of metastasis. Operative findings showed extension of the tumour to the surface of the RA and involvement of the RCA. The tumour was resected and a saphenous vein graft was anastomosed to the distal RCA. Histology confirmed angiosarcoma with a high mitotic rate and incomplete resection at the margin. A repeat operation with wider excision was performed with a clear histological margin. Five cycles of doxorubicin and
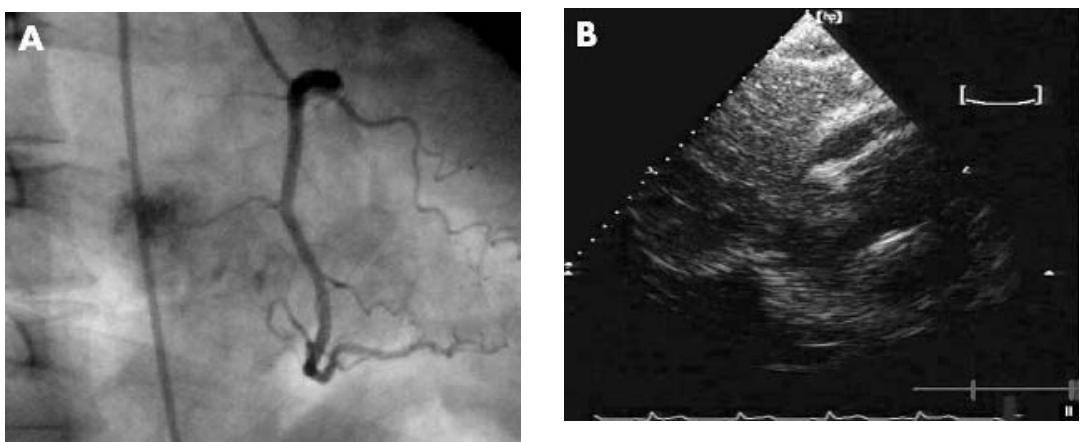

A tumour blush in the right atrium is seen during right coronary angiography.

ifosfamide chemotherapy were administered. Adjuvant radiotherapy to the site of the primary tumour was given. The patient died 11 months after primary diagnosis from CT proven metastatic disease.

This case demonstrates the unusual angiographic findings of a cardiac malignancy and its correlation with TTE and TOE echocardiographic images.

R Hillock

J Lainchbury

B Robinson richard.hillock@cdhb.govt.nz
Transoesophageal echocardiogram clearly showing the tumour and its extension. 